\title{
People With Disabilities Can Bring Strength to Your Business
}

\author{
Kimberly Eddleston (Northeastern University)
}

KEYWORDS: Entrepreneurship.

Many people have a very narrow view of disabilities -the factors that may limit someone's ability to perform a job. They focus on what a person can't do rather than what they are able to do.

Teresa O'Brien challenges those perceptions in this interview. O'Brien, who holds a National Certificate of Rehabilitation Counseling, developed a program that supports businesses in hiring people with all kinds of disabilities. These experiences have given her a broader view of what constitutes disability and the benefits people with disabilities can bring to a business. For example, a nurse who has developed a back problem may not be able to lift patients any more, but may shine in a desk job that requires knowledge of patient care. People whose brains can't process math but are exceptional in other areas will be assets on teams that capitalize on their strengths. And hiring people with disabilities can also help companies access a wider pool of talent in an era of profound labor shortages, and bring federal and state tax advantages.

For more information, visit:

Hiring People with Disabilities: US Department of Labor (https://www.dol.gov/general/topic/disability/hiring)

Four Ways to Hire More People with Disabilities (https://www.shrm.org/resourcesandtools/hr-topics/beh avioral-competencies/global-and-cultural-effectiveness/ pages/4-ways-to-hire-more-people-with-

disabilities.aspx)

\section{Disability Resources by State -- Download at top of this article}

